JOURNAL OF VETERINARY MEDICAL RESEARCH 2016, 23 (2): 184 - 190

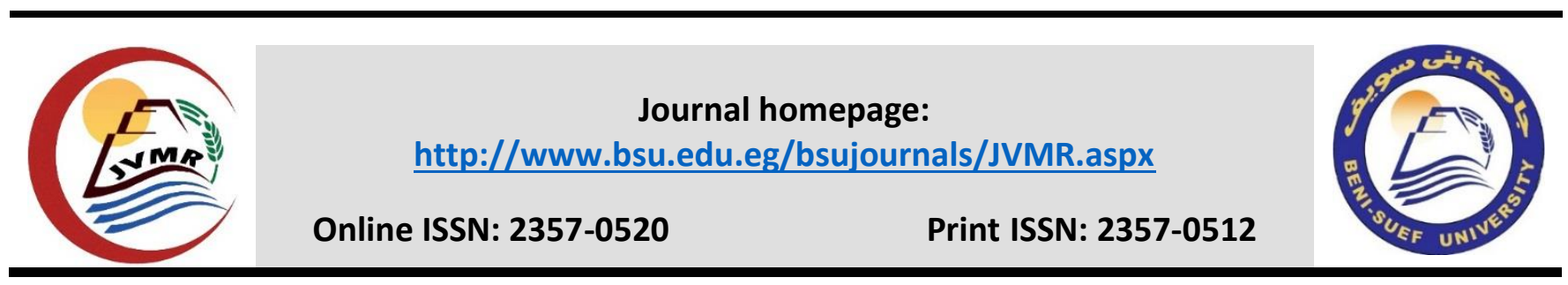

Original Research Article

\title{
Direct detection and identification of mycobacteria in bovine samples by PCR assay
}

\section{Walid Hamdy Hassan ${ }^{a,}{ }^{,}$, Essam Amin Nasr ${ }^{b}$, Hassan Mohamed Moussa ${ }^{c}$}

a Department of Bacteriology, Mycology and Immunology, Faculty of Veterinary Medicine, Beni-Suef University, Beni-Suef 6511, Egypt.

${ }^{b}$ Department of Tuberculosis, Bacterial Diagnostic Products Veterinary Serum and Vaccine Research Institute, Cairo, Egypt.

${ }^{\mathrm{c}}$ General Authorities for Veterinary Services.

\section{ABSTRACT}

Bovine tuberculosis, caused by Mycobacterium bovis, is a zoonotic disease causing approximately $6 \%$ of total human deaths. Its economic losses are not only a reduction of $10-20 \%$ in milk production and weight, but also infertility and condemnation of meat. Many serological tests are applied for detection of tuberculosis. ELISA test has the highest sensitivity and specificity than the other serological tests for the diagnosis of tuberculosis. Several forms of new technology were brought into the diagnostic approach to mycobacterial infection. The aim of this work was to detect bovine tuberculosis by application of different traditional tests and PCR. Tuberculin skin test was applied on 2650 cattle, only 63(2.4\%) were positive. Forty eight (76.2\%) of the slaughtered positive animals showed visible lesions (VL) while the other 15 (23.8\%) had non-visible lesions (NVL). Bacteriological examination of 10 selected tuberculin positive samples revealed $M$. bovis from 6 processed samples (60\%) while PCR and ELISA assays revealed positive in 8 cases $(80 \%)$ and 7 cases $(70 \%)$, respectively. It was concluded that PCR test is more sensitive and specific test to confirm the infection with tuberculosis.

\begin{tabular}{lc} 
ARTICLE INFO & \\
\hline Article history: & \\
Received: 11 & 2016 \\
Accepted: 12 & 2016 \\
Available Online: & 122016 \\
& \\
\hline Keywords: & \\
M. bovis, MOTT, tuberculin, \\
ELISA, PCR
\end{tabular}

\footnotetext{
* Corresponding author: Walid Hamdy Hassan; Department of Bacteriology, Mycology and Immunology, Faculty of Veterinary Medicine, Beni-Suef University, Beni-Suef 6511, Egypt. Tel. and Fax. (+2) 0822327982. Email: dr.walidh@yahoo.com
} 


\section{Introduction}

Bovine tuberculosis (bTB) caused by M. bovis; a member of the $M$. tuberculosis complex, is a zoonotic disease having considerable economic and public health implications (Neill et al., 1994; O'Reilly et al., 1995). It is a worldwide disease that causes a great harm on dairy farms and poses health risks to the population that consumes products of animal origin. It infected 50 million cattle worldwide resulting in economic losses of approximately $\$ 3$ billion (Hewinson, 2000).

The disease has been difficult to control in livestock because of the lack of an effective vaccine and the lack of a diagnostic assay with sufficient sensitivity and specificity to detect animals at all stages of infection. Currently the primary methods used for the detection of TB in cattle include the measurement of a delayed-type hypersensitivity (skin test) to purified protein derivative (PPD) (Monaghan et al., 1994).

Use of ELISA with the tuberculin skin test (Plackett et al., 1989) to overcome the problems of tuberculin development of an accurate serodiagnostic test requires a detailed understanding of the humeral immune response during bovine tuberculosis and, in particular, identification of the key antigens of $M$. bovis involved in antibody production (Lyashchenko et al., 1998).

Serological survey was carried out to determine the presence of antibodies against components of the culture filtrate protein extract by ELISA (Diaz-Otero et al., 2003), short term culture filtrate (ST-CF) was separated into molecular mass fractions and screened for recognition of ELISA (Pollock and Andersen, 1997).

Several forms of new technology were brought into the diagnostic approach to mycobacterial infection. Polymerase chain reaction (PCR) technique is much faster than culture and reduces the time for diagnosis from several months to 2 days (Bal et al., 1994).

PCR techniques are indispensable for the accurate detection of $M$. bovis in samples, even when organisms have become nonviable for culture or when there is an overgrowth by other mycobacteria, and differentiation of mycobacterial species (El-Seedy et al., 2013). PCR can be used for any sample material in theory. Combining PCR with culture is a highly sensitive and specific method to confirm M. bovis cultures (Godfoid et al., 2006).
The aim of the study was to detect directly Mycobacteria in tuberculin positive cattle by PCR compared with culture and ELISA assays.

\section{Materials and methods}

\subsection{Animals}

A total of 2650 cross-breed dairy cows from different governorates in Egypt were used in this study. All animals were tested with comparative tuberculin test (CTT) using bovine PPD (PPD-B).

2.2. Comparative Tuberculin Skin Test. (OIE, 2009)

Two sites on the right side of the mid-neck, 12 $\mathrm{cm}$ apart were shaved and the skin thicknesses were measured with calipers. One site was injected with $0.1 \mathrm{ml}$ Bovine PPD tuberculin; similarly $0.1 \mathrm{ml}$ avian PPD tuberculin was injected into the second site. After $72 \mathrm{hrs}$, the skin thickness at the injection sites was measured.

\subsection{Serum Samples}

From the positive reactors, about $10 \mathrm{ml}$ of blood were obtained aseptically from the jugular vein. The blood samples were left at room temperature for $2 \mathrm{hrs}$ in a slope position, then kept at $4^{\circ} \mathrm{C}$ overnight, centrifuged at $3000 \mathrm{rpm}$ for $15 \mathrm{~min}$, serum was aspirated, labeled then kept at $-20^{\circ} \mathrm{C}$ till use in serological test.

\subsection{Post mortem examination}

Careful inspection and examination was made simultaneously for the carcass, head and viscera of each slaughtered tuberculin positive reactor animals. The lung, liver, lymph nodes, spleen and heart received particular attention. Depending on the distribution of the lesions, the examined animals were categorized as: Animals with pulmonary TB lesions had lesions in the lung and related lymph nodes, animal with extra pulmonary lesions (had lesions in any parts other than thoracic cavity), animal with mixed TB lesions (had lesions in the lung and in any other organ of the body) and animals with generalized TB lesions.

For ELSA and PCR assays, samples from 10 positive tuberculin reactors were selected ( 8 of them showed different VL; 2 pulmonary, 2 digestive, 2 mixed and 2 generalized while 2 showed NVL in which Lymph nodes were included).

\subsection{Bacteriological isolation and identification of} the mycobacterial isolates

The organs, lymph nodes showing growth lesions prepared and stained with Ziehl Neelsen stain. 
Samples were cultured on Lowenstein Jensen medium after being decontaminated with $\mathrm{H}_{2} \mathrm{SO}_{4}$. The isolates were identified by conventional methods according to Kubica (1973).

\subsection{Enzyme Linked ImmunoSorbent assay} (ELISA)

ELISA was applied on 10 selected samples. According to Collee et al. (1996) using ESAT 6/P antigen. The optical density was measured at $405 \mathrm{~nm}$ using spectra III ELISA reader. Sample was considered positive if yielded a mean OD equal to or greater than the cut off value that is calculated according to El-Seedy et al. (2013) which is equal to the mean OD of negative serum plus two standard deviations.

\subsection{PCR.}

PCR, using Oligonucleotide primers that amplify a 800bp fragment in $R D 8$ region of $M$. bovis, was applied on the same 10 samples selected for ELISA.

Primers:

Primer 1 (Forward primer): 5'- TCT TGC GGC CCA ATG AAT - 3'

$\sim$ Primer 2 (Reverse primer): 5'- GGT GTG ATT TGG TGA GAC GAT- 3'

Amplification by PCR (Noordhock et al., 1996)

- Initial denaturation step $94^{\circ} \mathrm{C}$ for 4 min.

- First cycle; denaturation at $94^{\circ} \mathrm{C}$ for $45 \mathrm{sec}$.

- Annealing at $56^{\circ} \mathrm{C}$ for $45 \mathrm{sec}$.

- Extension at $72^{\circ} \mathrm{C}$ for $45 \mathrm{sec}$.

- Repeat for another 39 cycles.

- Final extension at $72^{\circ} \mathrm{C}$ for $10 \mathrm{~min}$.

\section{Results}

\subsection{Tuberculin test}

Tuberculin skin test was applied on 2650 cattle. Only 63 animals (2.4\%) were positive reactors.

\subsection{Post mortem slaughtered tuberculin reactor} cattle

Out of 63 tuberculin-reactors; 48 (76.2\%) showed visible lesions (VL); of which 40 (83.3\%) were localized (respiratory, digestive or mixed) while 8
(16.7\%) were generalized. On the other hand, 15 reactors $(23.8 \%)$ showed NVL (Table 1).

\subsection{Bacteriological examination of the tuberculin reactors.}

Bacteriological examination of the tuberculin reactors revealed that the total acid fast bacilli recovered from 63 slaughtered tuberculin reactors cattle were $50(79.4 \%)$ isolates which were identified according to the morphological characters, growth rate, pigmentation, growth at different temperatures and biochemical tests into $47 \mathrm{M}$. bovis $(74.6 \%)$ as well as $3(4.8 \%)$ Mycobacteria other than TB (MOTT) (Table 2).

3.4. Results of $M$. bovis isolation, PCR test and ELISA test from selected tuberculin reactor samples.

Out of 10 samples from 10 positive tuberculin reactors selected for ELSA and PCR assays, 8 samples $(80 \%)$ were positive for PCR while 7 samples (70\%) were positive for ELISA test using ESAT 6/P antigen. Bacteriological examination of the 10 selected samples revealed that $6 \mathrm{M}$. bovis isolates (60\%) were recovered (Table 3).

Results of Mycobacteria isolation, PCR test and ELISA test in relation to different $\mathrm{P} / \mathrm{M}$ lesions; from selected tuberculin reactor samples, were illustrated in Table 4. Eight samples were positive for PCR of which 2 generalized, 2 pulmonary, 2 mixed and 1 digestive lesions as well as 1 NVL. On the other hand, 2 negative PCR cases were recorded in digestive calcified form and NVL. Seven samples were positive for ELISA of which 2 generalized, 2 pulmonary, 1 mixed and 1 digestive lesions as well as $1 \mathrm{NVL}$. On the other hand, 3 negative ELISA cases were recorded in digestive calcified, mixed calcified and NVL. Bacteriological isolation revealed that $6 \mathrm{M}$. bovis isolates arranged as 2 generalized, 2 pulmonary, 1 of both mixed and digestive lesions. Moreover, MOTT were recovered from 3 samples; digestive calcified, mixed calcified and NVL. On the other hand, 1 NVL showed negative isolation of mycobacteria.

\section{Table 1. The post mortem (PM) findings of tuberculin reactor cattle.}

Total slaughtered animals (Positive reactors)

\begin{tabular}{|c|c|c|c|c|c|c|c|c|}
\hline $\begin{array}{c}\text { reactors) } \\
63\end{array}$ & \multicolumn{2}{|c|}{ Total } & \multicolumn{2}{|c|}{ local } & \multicolumn{2}{|c|}{ general } & \multicolumn{2}{|c|}{ (1) } \\
\hline \multirow{2}{*}{63} & No. & $\%$ & No. & $\%^{*}$ & No. & $\%{ }^{*}$ & No. & $\%$ \\
\hline & 48 & 76.2 & 40 & 83.3 & 8 & 16.7 & 15 & 23.8 \\
\hline
\end{tabular}

Visible lesions (VL)

$\%^{*}$ : Percentage according to the total No. of VL.
Non Visible Lesions

(NVL)

$\%$ : Percentage according to the total No. of Positive reactors. 
Table 2. Bacterial identification of mycobacterial isolates from tuberculin reactor cattle.

No. of Positive reactors

\begin{tabular}{cccccc}
\multicolumn{2}{c}{ M. bovis } & \multicolumn{2}{c}{ MOTT } & \multicolumn{2}{c}{ Total isolates } \\
\hline NO. & $\%$ & NO. & $\%$ & NO & $\%$ \\
\hline 47 & 74.6 & 3 & 4.8 & 50 & 79.4 \\
\hline
\end{tabular}

MOTT: Mycobacteria Other Than Tuberculosis. $\quad \%$ : Percentage according to the total No. of Positive reactors.

Table 3. Relationship between results of $M$. bovis isolation, PCR and ELISA in tuberculin reactor cattle.

\begin{tabular}{lccccc}
\multirow{2}{*}{ Assay } & No. of & \multicolumn{2}{c}{ positive } & \multicolumn{2}{c}{ Negative } \\
\cline { 3 - 5 } & Sample & No. & \% & No. & \% \\
\hline M. bovis isolation & & 6 & 60 & 4 & 40 \\
PCR & 10 & 8 & 80 & 2 & 20 \\
ELISA & & 7 & 70 & 3 & 30 \\
\%: Percentage according to the No. of samples. & & \multicolumn{3}{c}{}
\end{tabular}

$\%$ : Percentage according to the No. of samples.

Table 4. Results of mycobacterial isolation, PCR and ELISA in relation to different P/M lesions of tuberculin reactor cattle.

\begin{tabular}{ccccc}
\hline Samples & P/M finding & Mycobacteria isolation & ELISA & PCR \\
\hline 1 & Generalized & M. bovis & $+\mathrm{ve}$ & $+\mathrm{ve}$ \\
2 & Generalized & M. bovis & $+\mathrm{ve}$ & $+\mathrm{ve}$ \\
3 & Pulmonary & M. bovis & $+\mathrm{ve}$ & $+\mathrm{ve}$ \\
4 & Pulmonary & M. bovis & $+\mathrm{ve}$ & $+\mathrm{ve}$ \\
5 & Digestive & M. bovis & $+\mathrm{ve}$ & $+\mathrm{ve}$ \\
6 & Digestive Calcified & MOTT & $-\mathrm{ve}$ & $-\mathrm{ve}$ \\
7 & Mixed & M. bovis & $+\mathrm{ve}$ & $+\mathrm{ve}$ \\
8 & Mixed Calcified & MOTT & $-\mathrm{ve}$ & $+\mathrm{ve}$ \\
9 & NVL & MOTT & $-\mathrm{ve}$ & $-\mathrm{ve}$ \\
10 & NVL & $-\mathrm{ve}$ culture & $+\mathrm{ve}$ & $+\mathrm{ve}$ \\
\hline
\end{tabular}

\section{Discussion}

Bovine tuberculosis caused by $M$. bovis, characterized by progressive developed granulomatous lesions (tubercles) in any body organ, and affected a large number of species. Tuberculosis is now generally perceived to represent the greatest threat to cattle health and incidence of bovine tuberculosis is rising, both in numbers of herd affected and in the number of cases per affected herd (Cobner, 2003). Bovine tuberculosis infected so million cattle world-wide resulting in economic losses of approximately 3 billion (Hewinson, 2000).

As shown in table (1), out of 63 tuberculinreactor animals; $48(76.2 \%)$ showed VL including $40(83.3 \%)$ localized lesions; either respiratory, digestive or mixed, $8(16.7 \%)$ generalized lesions and $15(23.8 \%)$ NVL. These results are more or less similar to those recorded by Adawy (1986) where generalized TB lesions were seen in $9.07 \%$ of tuberculin positive cow. Moreover, Nasr (1997) reported that, out of 66 reactor cattle, 60 cattle were slaughtered, 44 (73.4\%) had VL and 16(26.6) with NVL. Hassan (2008) revealed that out of 115 tuberculin reactor animals, $85(73.91 \%)$ showed VL and 30(26.09\%) had NVL. El-Seedy et al. (2013) detected VL in about $68.1 \%$ of the tuberculin reactor cattle while the NVL were seen in $31.9 \%$.

Results illustrated in Table 2 showed the results of bacteriological examination of the tuberculin reactors cattle where the total acid fast bacilli recovered from 63 slaughtered tuberculin reactors were $50(79.4 \%)$ of them $74.6 \%$ were $M$. bovis and $4.8 \%$ were MOTT. These results coincided with those recorded by Calaxton et al. (1979) who found that out of 642 lesions suspected to be tuberculous, (62\%) yielded $M$. bovis and (3.6\%) other than mycobacteria. Meanwhile, the results are in agreement with El-Sabban (1980) who isolated $M$. bovis $(71 \%)$ from tuberculous samples in Egypt. On the other hand, the present results differed from those reported by Choi (1981) who showed that bacteriological examination of 76 tuberculin reactors cattle and isolated $70 \quad(92.1 \%)$ strain of 
mycobacteria, $33(47.1 \%)$ strain identified as $M$. bovis and 37 strains other than mycobacteria. The recovery rate of $M$. bovis figured up to $74.6 \%$ was nearly as that reported by Gouello et al. (1988) (69\%). Lower M. bovis recovery rates $(41 \%, 35.4 \%$, $29.1 \%$ and $20.2 \%$ ) were reported by Beck and Bibrack (1971), Osman (1974), Gallo et al. (1983) and Lesslie and Birn (1970), respectively. AbouEisha et al. (1995) reported $42.9 \%$ recovery rate. On the other hand Choi (1981) in Korea reported a much higher isolation rate amounting to $92.1 \%$. These results based mainly on the actual disease status present in the tested herd to some extent on the experience of the investigators as well as the technique used for decontamination of tissue specimens. Other authors reported much lower $M$. bovis recovery (Parlas and Rossi, 1964) (14.8\%), (Payeur and Marquardt, 1988) (5.6\%). A low M. bovis recovery rate $(14.8 \%)$ may be on the expense of other mycobacteria, which may be noticeable in countries where $M$. bovis extirpated from their cattle population, whereas $M$. avium constitutes a problem among cattle herds, which is the case in Germany (Killian, 1982). The recovery rate of atypical mycobacteria was $6.3 \%$, and $3.1 \%$, which is higher than that reported by Oliviera et al. (1983) (0.1\%). However, Choi (1981) reported that $48.7 \%$ of the reactors were infected with atypical mycobacteria.

Serological assays are generally simple, rapid and inexpensive, but the development of improved serodiagnostic assays also require understanding of the bTB humeral immune mechanism as it is characterized by highly heterogeneous antigen recognition (Lyashchenko et al., 1998).

PCR technique is much faster than culture, reducing the time for diagnosis to 2 days and providing the ability to detect the presence of $M$. bovis in samples even when organisms have become nonviable for culture or when there is an overgrowth by other mycobacteria or low number of mycobacteria present in the sample (El-Seedy et al., 2013). It offers a powerful diagnostic method for detection of M. bovis in animal samples; it is fast, sensitive, and specific.

Comparison between $M$. bovis isolation, PCR test and ELISA test from 10 selected tuberculin reactor samples were illustrated in Table 3. PCR showed high sensitivity (80\%) followed by ELISA $(70 \%)$ and finally $M$. bovis isolation (60\%).

Furthermore, mycobacterial isolation, PCR test and ELISA test in relation to different P/M lesions; from selected tuberculin reactor samples, were illustrated in Table 4. All samples selected from generalized $(n=2)$ and pulmonary $(n=2)$ lesions showed positive $M$. bovis isolation, PCR and ELISA tests. Only one sample from each of those with digestive and mixed forms ( $n=2$ of each) showed positive $M$. bovis isolation, PCR and ELISA tests. Meanwhile the other sample of each form which was calcified showed MOTT isolation and negative ELISA test while PCR gave positive result only with mixed calcified sample. On the other hand, one of the NVL $(n=2)$ showed MOTT isolation and associated with negative ELISA and PCR assays. The other NVL showed negative mycobacterial isolation but associated with positive ELISA and PCR assays.

False negative ELISA results explained by the fact that low titer of antibodies to mycobacterial antigens which may be associated with heavy infection and that antigens may be released into the blood circulation and cause temporary suppression of antibody formation (Krambovitis, 1986) and that agree with Thorns and Morris (1983) who cleared the level of specific antibodies in many $M$. bovis infected cattle may be low or undetectable. Again this is supported with Amadori et al. (1998) who pointed that antibodies to mycobacterial antigens were investigated with various rates of success since the humeral immune response to $M$. bovis is late and irregular during the course of the disease. In the current study there were not false negative results.

Collectively, the present results coincided with those of Wards et al. (1995), Nasr et al. (2009) and El-Seedy et al. (2013) who proved that PCR is more sensitive than ELISA technique. The current results were higher than that obtained by Liebana et al. (1995) as it was $71.4 \%$ positive. So, it was concluded that PCR could be used as rapid screening technique that would be complementary to culture for the routine diagnosis of bovine tuberculosis, faster than culture and may be able to detect the presence of $M$. bovis in samples even when organisms have become non-viable. Although direct PCR can produce a rapid result, it is recommended that culture should be used in parallel to confirm the existence of a viable $M$. bovis in the positive reactor animals. 


\section{Conclusion}

It is concluded that PCR was reliable laboratory test for diagnosis and confirmation the results of tuberculin test for detection of $M$. bovis infection.

\section{Acknowledgements}

Great thanks for the staff of the Department of Bacteriology, Mycology and Immunology, Faculty of Veterinary Medicine, Beni-Suef University for the great effort during the entire practical section as well as the moral support.

\section{References}

Abou-Eisha AM, El-Attar AA, Elsheary MN (1995). Bovine and atypical mycobacterial infection of cattle and buffaloes in Port Said Province, Egypt. Assiut Vet. Med. J., 47: 152-162.

Adawy AT (1986). Studies on tuberculosis in slaughtered cattle. Ph.D. Thesis, Faculty of Vet. Med. Cairo University.

Amadori M, Tameni S, Scaccaglia P, Archetti IL, Quondam RG (1998). Antibody tests for identification of Mycobacterium bovis infected bovine herds. J. Clin. Microbiol., 36: 566-568.

Bal GH, Hwang HS, Shon BW (1994). Detection of M. bovis lesions in slaughtered dairy cattle using modified culture medium and the polymerase chain reaction. Korean J. Vet. Public-Health, 18(3):183-190.

Beck G, Bibrack B (1971). Pathological, histological and cultural diagnosis of mycobacterial infections with special reference to meat inspection regulations. Tierarztl. Umschau, 26(5):196-201.

Calaxton PD, Eamens GJ, Mylrea PJ (1979). Laboratory diagnosis of bovine tuberculosis. Aust. Vet. J. 55(11):514-520.

Choi CS (1981). Mycobacteruim isolated from man, animals and soil in Korea, 1968-1980: A review. Korean J. Vet. Public Health, 5(1):49-64.

Cobner A (2003). Bovine tuberculosis; clinical update and on farm advice. In-practice, 25(10), 606-613.

Collee JG, Fraser AG, Marmion BP, Simmons A (1996). Mackie, McCortney Practical Medical Microbiology $14^{\text {th }}$ Ed., 838-841. Churchill Livingstone, New York Edinburgh, London.

Diaz-Otero F, Banda-Ruiz V, Jaramillo-Meza L, Arriaga-Diaz C, Gonzalez-Salazar D, EstradaChavez C (2003). Identification of Mycobacterium bovis infected cattle by immmmunological and molecular methods. Veterinaria-Mexico.; 34(1):13-26.

El-Sabban MS (1980). Bovine TB and its extent of spread as a source of infection to man and animals in A.R.E. Scientific report 1972-1980 on the national T.B-Res. project by the Academy of Sc. Res. \& Technology.

El-Seedy FR, Radwan IA, Hassan WH, Nasr EA, Abed AH, Moussa IMI (2013). The correlation between $M$. bovis isolation and ELISA using $P P D-B$ and ESAT6-CFP10 mixture on the sera of tuberculin reactor cattle and buffaloes. J. Food Agric. Environ., 11(1):489-494.

Gallo JAG, Veitia F, Remon S, Delgado L (1983). Mycobacteria isolated from cattle reacting to tuberculin tests. Rev. Cubana Cienc. Vet., 14(3): 173-176.

Godfoid J, Govaerts M, Walravens K (2006). Clinical utility of a PCR-based testing strategy for the diagnosis of Mycobacterium bovis infection in cattle. Vet. Microbiol., 112: 387-389.

Gouello L, Aubry C, Carbonelle B (1988). Diagnosis of bovine tuberculosis: bacteriological survey in abattoirs. Point Vet., 20(4): 525-530.

Hassan NRA (2008). Emergency mycobacterium tuberculosis complex organisms: advances in diagnosis and drug resistance. Ph.D. Thesis, Bacteriology, Immunology, Mycology, Fac. Vet. Med., Cairo University.

Hewinson G (2000). Development of vaccines against bovine tuberculosis. $2^{\text {nd }}$ International Veterinary Vaccines and Diagnosties Conference Oxford, 23-28 July.

Killian H (1982). Occurrence of mycobacteria in lymph nodes and muscles of slaughtered cattle and swine with reference to isolated tuberculosis of lymph nodes. Inaugural-Dissertation, Fach berich Veterinar medizin, Freie Universital Berlin, 112 PPD.

Krambovitis E (1986). Detection of antibodies to Mycobacterium tuberculosis plasma membrane antigen by enzyme linked immuno sorbent assay. J. Med. Microbiol., 21(3):257-264.

Kubica GF (1973). Differential identification of mycobacteria. VII. Key features for identification of clinically significant mycobacteria. Am. Rev. Respir. Dis., 107: 9-21.

Lesslie IW, Birn KJ (1970). Mycobacterium avium infections in cattle and pigs in Great Britain. Tubercle, Land 51: 446-451. 
Liebana E, Aranaz A, Mateos A, Vilafranca M, Domingo M, Dominguez M (1995). Simple and rapid detection of $M$. Tuberculosis complex organisms in bovine tissue samples by PCR. J. Clin. Microbiol., 33(1):33-36.

Lyashchenko KP, Poollock JM, Colangeil R, Gennaro ML (1998). Diversity of antigen recognition by serum antibodies in experimental bovine tuberculosis. Infect. immun., 66(11):5344-5349.

Monaghan ML, Doherty ML, Kazda JE, Quinn PJ (1994). The tuberculin test. Vet. Microbiol., 40: 111-124.

Nasr EA (1997). Studies on atypical mycobacterial microorganisms. Ph.D. in Microbiology, Zagazig University. Fac. of Vet. Med., Moshtohor.

Nasr EA, Soliman YA, Alexan AF, Zakhary EM (2009). Differentiation between Mycobacterium tuberculosis and Mycobacterium bovis using genetic approach. Egypt J. Appl. Sci., 24: 1-12.

Neill SD, Cassidy J, Hanna J, Mackie DP, Pollock JM, Clements A, Walton E, Braysson DG (1994). Detection of $M$. bovis infection in skin testnegative cattle with an assay for bovine interferon- gamma. Vet. Rec., 135 (6): 134-135.

Noordhock GT, Kolk AH, Bjune G, Catty D, Dale JW and Fine PE (1996). Sensitivity specificity of PCR for detection of Mycobacterium tuberculosis: a blind comparison study among seven laboratories. J. Clin. Microbiol, 32: 227284.

Office International des Épizooties (OIE) Terrestrial Manual (2009). Bovine tuberculosis. In: Manual of Diagnostic Tests and Vaccines for Terrestrial Animals. Part 2, Section 2.4. World Organization for Animal Health, chapter 2.4.7 Vol.2.,pp: 1-16.

Oliviera SJ, Piantac RE, Azevedo CA, Antunes CA, Silva FM (1983). Veterinary public health. A study of tuberculosis in dairy cattle. Bol. Oficina Sanit. Panam., 94 :142-149.

O'Reilly LM and Daborn CJ (1995). The epidemiology of Mycobacterium bovis infections in animals and man: a review. Tuberc. Lung Dis., 76:1-146.

Osman K (1974). Studies on acid fast microorganisms in some domesticated animals with special reference to atypical mycobacteria group. Ph.D. Thesis (Microbiology), Cairo University.
Parlas M, Rossi L (1964). Causes of recurrence of tuberculosis in TB free herds. Vet. Med. 9: 1-10.

Payeur JB, Marquardt JG (1988). Mycobacterial isolated from submissions at NVSL National Veterinary Services Laboratories during Four years 83- 87. Proc. US Anim. Hlth. Assoc., 92: 457- 477.

Plackett R, Ripper J, Comer LA, Small K, Witte K, Melville L, Hides S, Wood PR, De-Witte K (1989). An ELISA for the detection of anergic tuberculous cattle. Aust. Vet. J., 66(1): 15-19.

Pollock JM, Andersen P (1997). Predominant recognition of the ESAT-6 protein in the first phase of infection with M. bovis in cattle. Infect. Immun., 65 (7): 2587-2592.

Thorns CJ, Morris JA (1983). The immune spectrum of Mycobacterium bovis infections in some mammalian species. Vet . Bull., 53 (6): 543-547.

Wards BJ, Collins DM, Lisle GW, De- Lisle GW (1995). Detection of $M$. bovis in tissues by polymerase chain reaction. J. Vet. Microb., 43: 227-240. 